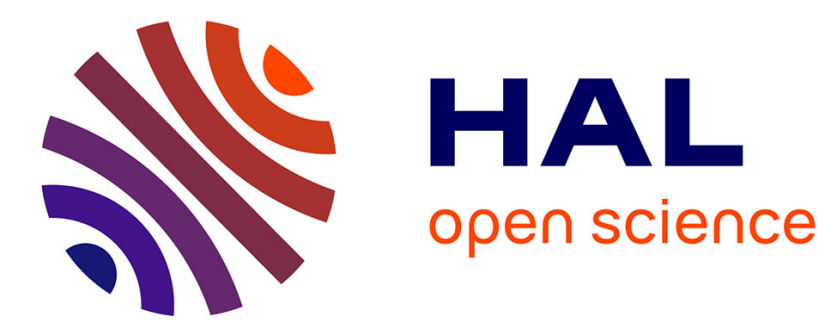

\title{
Should we teach primary pupils about chemical change?
}

George Papageorgiou, Maria Grammaticopoulou, Phil Michael Johnson

\section{To cite this version:}

George Papageorgiou, Maria Grammaticopoulou, Phil Michael Johnson. Should we teach primary pupils about chemical change?. International Journal of Science Education, 2010, 32 (12), pp.16471664. 10.1080/09500690903173650 . hal-00608034

\section{HAL Id: hal-00608034 https://hal.science/hal-00608034}

Submitted on 12 Jul 2011

HAL is a multi-disciplinary open access archive for the deposit and dissemination of scientific research documents, whether they are published or not. The documents may come from teaching and research institutions in France or abroad, or from public or private research centers.
L'archive ouverte pluridisciplinaire HAL, est destinée au dépôt et à la diffusion de documents scientifiques de niveau recherche, publiés ou non, émanant des établissements d'enseignement et de recherche français ou étrangers, des laboratoires publics ou privés. 


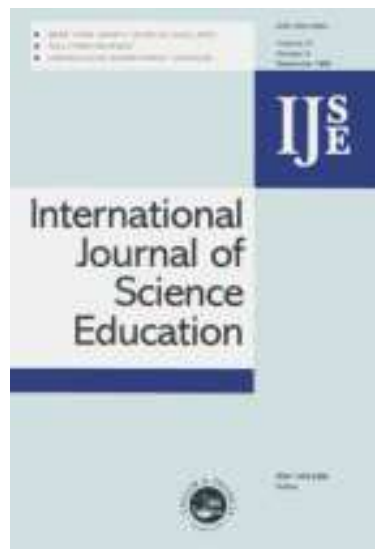

\section{Should we teach primary pupils about chemical change?}

\begin{tabular}{|r|l|}
\hline Journal: & International Journal of Science Education \\
\hline Manuscript ID: & TSED-2009-0146.R1 \\
\hline Manuscript Type: & Research Paper \\
\hline Keywords: & chemistry education, primary school \\
\hline Keywords (user): & Particle ideas, pupils' explanations, chemical changes \\
\hline \multicolumn{2}{|l}{} \\
\end{tabular}

\section{(5) ScholaroNE \\ Manuscript Central}


Running head: Teaching primary pupils about chemical change

\title{
Should we teach primary pupils about chemical change?
}

\begin{abstract}
Thirty six pupils from three $6^{\text {th }}$ grade classes (ages 11/12, $n=75$ ) in Greece were interviewed pre and post intervention in a piece of research on explanations of chemical phenomena. Software concerning chemical phenomena was incorporated in a teaching scheme, where the particle theory was used. After 13 hours intervention, pupils' explanations were categorized in five discrete categories. Only a few pupils could give satisfactory explanations, involving the integration of particle ideas at the level of atoms. The idea of chemical change seemed to be very difficult for the majority of pupils. Implications for the teaching of chemical phenomena at young ages are discussed.
\end{abstract}

\section{Keywords}

Chemical phenomena, Particle ideas, Pupils' explanations

\section{Introduction}

Pupils' understanding of chemical phenomena has been and continues to be the focus of much research (e.g. Ahtee \& Varjola, 1998; Andersson, 1990; Stavridou \& Solomonidou, 1998; Author \#3, 2000, 2002; Boo \& Watson, 2001; Brosnan \& Reynolds, 2001; Solsona, Izquierdo \& De Jong, 2003; Calik \& Ayas, 2005; Liu \& Lesniak, 2006; Cokelez, Dumon \& Taber, 2008; Driver, 1985). Studies have covered 
Running head: Teaching primary pupils about chemical change

a range of ages from primary school through to undergraduate. The main impression from reading this work is that the idea of a chemical change is far from most pupils' way of thinking. Even the recognition of a chemical change is not easy, especially for younger pupils. At older ages recognition is achieved more frequently, but the understanding of chemical phenomena and the possibility of their explanation remains a problem. At issue is whether pupils see chemical change as a change of substance, where old substances go out of existence and new substances are created.

In an influential review of pioneering work, Andersson identified four categories of pupils' alternative responses to various chemical phenomena (Andersson, 1990):

A) Disappearance - a substance simply disappears, e.g. e.g. 'The missing part of a candle during burning disappears', or 'a small part of the fuel of a car becomes exhausts, whereas the main part disappears'.

B) Displacement - a substance appears in a given place because it has been displaced from somewhere else... e.g. 'the water that is produced from burning wood was inside the wood'

C) Modification - what appears to be a new substance is the same substance as before in a modified form, e.g. 'when alcohol is burning vapours of alcohol are produced'

D) Transmutation - in the case of elementary substances, one element is transformed into a new one, e.g. iron into carbon on heating; or 'burning wax becomes flame' (substance to energy); or 'droplets on glass above a burning candle are formed due to the heating of the flame' (energy to substance) 
Running head: Teaching primary pupils about chemical change

However, in defining these categories a key question is whether pupils actually hold the concept of a substance. In a study exploring pupils' (aged 12 to 18) ability to distinguish between physical and chemical changes, Stavridou and Solomonidou (1989) report that properties were not used to identify substances. Thus, the pupils had no means of distinguishing between physical and chemical changes. Talanquer (2006) and Author \#3 (2000) have found pupils using origin rather than here and now properties to identify samples of material. The thinking is in terms of where something has come from and what has been done to it. Similarly, at more advanced levels, Taber (2001) notes students thinking that a chloride ion is only bonded to the specific sodium atom that donated an electron to that particular anion. In studies throughout the literature, where apposite, subjects have not volunteered scientific thinking on substance identity. Andersson's displacement and modification categories are both consistent with 'origin' thinking. From this perspective, the transmutation category is more problematic. Without the concept of a substance, pupils cannot conceive of chemical change as a possibility so it seems unlikely that they would think of transmutation in the scientific sense. A pupil saying the black powder produced on heating iron is 'carbon' could simply be using the term as a description - the powder looks like carbon. (Transmutation between substance and energy is even more problematic). Similarly, disappearance is a description of what is seen (or not) without any implication for what has happened to the matter.

From later work, Stavridou and Solomonidou (1998), suggest three categories for pupils' conceptions of events that are chemical changes (to the scientist). The categories represent stages by which the concept of chemical change (a chemical reaction) is constructed with increasing age (from 12 to 18). In the first stage, chemical reaction cannot be identified as a change. Young pupils see these 
Running head: Teaching primary pupils about chemical change

phenomena just as 'events' where something happens, which are only described phenomenologically (e.g. a colour change, bubbles). Andersson's A and B categories, would map to this first stage. On our interpretation, Andersson's transmutation category (D) would also match the first stage. If pupils do not hold the concept of a substance, such responses are descriptions. In Stavridou and Solomonidou's second stage, pupils interpreted phenomenon as a process of mixing, where two things are mixed up and something else is produced. It had to be two things and the something else simply needed to be different. Thus the dissolution of sugar in water qualified. The pupils did not think in terms of new substances being produced. In the third stage, the older pupils (mostly age 18) could define a chemical change in terms of changes in molecular structures. However, only one student actually connected the changes in structure to the formation of a new substance on the macroscopic scale. Similarly, in a study involving 18 year old chemistry students $(n=51)$ in Spain (Solsona et al., 2003), only $8 \%$ were able to relate the macroscopic meaning of chemical change to the particulate meaning. A third of the students showed signs of developing an atomic explanation without paying attention to macroscopic phenomena.

In common with Stavridou and Solomonidou's second stage, Author \#3 (2000, 2002) found examples of pupils thinking only in terms of mixing. Thus copper oxide is viewed as a mixture of two substances, copper and oxygen rather than a single substance with its own identity. Pupils' difficulties in distinguishing between mixtures and compounds are well known (e.g. Briggs \& Holding, 1986; Stains \& Talanquer, 2007). Talanquar (2007) reports a very high prevalence of additive type thinking amongst undergraduate students on a general chemistry course. In this heuristic, a blue substance reacting with a yellow substance would give a green substance. The 
Running head: Teaching primary pupils about chemical change

notion of a new substance with emergent properties seems to be a particularly difficult idea.

However, there is evidence that secondary pupils can come to an understanding of chemical change. By the end of a three year longitudinal study (following pupils from age 11 to 14) one third of 33 pupils had accepted the phenomenon (Author\#3, 2000, 2002). These pupils understood copper oxide to be a substance in its own right and could relate the molecular composition of water $(\mathrm{H}$ and $\mathrm{O}$ atoms) to its singularity as a substance (e.g. why water has one boiling point). Previously, these pupils had interpreted chemical changes as either a modification (the same substance changed to a different form) or as simply mixing (or separation of a mixture). The breakthrough for the pupils coincided with the explanation in terms of atoms, introduced in the third year of the study. Before that, chemical changes had been described on a macroscopic basis with attention to using melting and boiling points to identify substances. However, the pupils did not find a properties approach, by itself, convincing. A mechanism that could explain why it was possible for substances to change into other substances was needed. Furthermore, a sound understanding of 'basic' particle theory seemed to be a precondition for ideas of atoms to make sense. However, for those that had made good progress with the idea of chemical change, a complete understanding of a lighted candle was not reached. This example of chemical change seems to present an especially high challenge (Meheut, Saltiel \& Tiberghien, 1985; Watson, 1995; Boajoaude, 1991).

An understanding of chemical change involves the concept of a substance at both the macroscopic and particulate levels. The literature suggests the macroscopic understanding of chemical change (as a change of substance) may be dependent on an atom level explanation. However, we have argued elsewhere that standard approaches 
Running head: Teaching primary pupils about chemical change

to introducing particle theory actually overlook the concept of a substance (Author \# 3 \& \#1, 2009). Particle theory is introduced within a 'solids, liquids and gases' framework, where the emphasis appears to be on the room temperature states of materials (regardless of whether the material is a substance or a mixture of substances). The danger is that pupils are led to believe there are three fundamental kinds of matter - 'solids', 'liquids' and gases' (Author \#3, 1996). A particle model should conceptualize the differences between the states indeed, but the basis should be on why a substance can be in any of the three states. We believe the 'solids, liquids and gases' framework is a contributing factor to pupils' well known difficulties with understanding particulate ideas. For example, if pupils think there are there types of matter, there is no need to think beyond three types of particle which carry the macroscopic properties ('solid' particles, 'liquid' particles and 'gas' particles). Exposure to the 'solids, liquids and gases' framework could also be contributing to pupils' difficulties with chemical change. For example, pupils have difficulty in understanding how 'a gas' can mix with 'a solid', let alone interact to produce new substances which could emerge in any state (Author \#3, 2002). To understand chemical change one needs to see beyond the room temperature state. It is also difficult to see how ideas of atoms can be developed at a second level of particle theory without a sound understanding at the first level which accounts for the states.

\section{The research question}

In previous work (Author \#1 \& \#3, 2005; Author \#1, \#3 \& other, 2008; Author \#3 \& \#1, 2009) we have explored the use of a substance-based approach to introduce particle theory to primary school pupils (ages 9 -12) in the context of physical phenomena. The results of these studies have been encouraging and suggest that 


\section{Methodology}

The sample

Three $6^{\text {th }}$ grade classes (ages $11 / 12, n=75$ ) of two primary schools in a town in North Greece took part in this research. The town has a socioeconomic level around the average for the country. Both schools are designated as normal urban public schools, with mixed ability pupils. Prior to our intervention, all pupils had followed the National Science Curriculum for Greece (Greek Pedagogical Institute, 1999) using the same textbooks. Therefore, the pupils had not been taught about chemical 
Running head: Teaching primary pupils about chemical change

changes. Some particle ideas had been meet previously in an electricity topic where an electric current was explained in terms of moving electrons.

\section{The procedure of the intervention}

The pupils attended a 13-lessons course working on PC's in groups of threes under the direction of the teacher (author \#2). Each lesson lasted one hour and had three parts:

- An initial class discussion which made connection with previous knowledge and introduced the main part of the lesson.

- A main part, where groups were navigating through specific units of the software with the help and supervision of the teacher. Here, pupils were asked to predict, observe or/ and explain 'key points' and answer particular questions on a worksheet. A process similar to Predict-Observe-Explain (POE) tasks described by Tao \& Gunstone (1999).

- A final teacher-led class discussion where pupils expressed their views on the key points of the lesson and conclusions were drawn.

\section{The teaching scheme}

The content of the teaching scheme is outlined in Table 1 . Sections 1 to 5 which introduce the particle model in the context of physical phenomena are similar to schemes used in previous research by the authors (Authors \#1 \& \#3, 2005 ; Authors \#1, \#3 \& others, 2008). Sections 6 to 9 address chemical change. The software and teaching scheme were designed in conjunction with each other.

[Insert Table 1 about here] 
Running head: Teaching primary pupils about chemical change

In section 1 the distinction between properties that only depend on the material and those that also depend on the object (amount of material and design) is made. Melting behaviour is then used to define a substance (section 2), and the particle theory is introduced to explain why a sample of a substance could change between the solid and liquid states (section 3). A simple particle model is presented (using animations), where:

- A sample of a substance is a collection of particles

- The particles of one substance are all the same and have a particular shape (there is no distinction of particles into molecules, atoms or ions, yet).

- The particles have an 'ability to hold' on to each other - this is different for different substances.

- The particles are always moving in some way - they have energy of movement.

- Heating gives particles more 'energy'.

'Ability to hold' is a key component of this introductory model. As a characteristic of the particles of a particular substance, 'ability to hold' does not change with change of state. This directs attention to the change in the 'energy' of the particles to explain a change of state. Thus, change of state (section 4) is explained by comparing the 'energy' of the particles (which changes with temperature) with the 'ability of the particles to hold' on to each other (which does not change). Therefore, any substance could be in any of the three states. Different strengths of 'hold' account for different melting and boiling points and hence different room temperature states. In this way the approach seeks to avoid giving the impression that 'solids', 'liquids' and 'gases' are three separate types of matter (Author \#3 \& \#1, 2009). 
Running head: Teaching primary pupils about chemical change

The concept of mixing is introduced in section 5 and analysed at the particle level due to its importance with respect to chemical change. Mixing is a precondition for a chemical change - chemical change is much more than just mixing. Air was studied as a mixture, as well as the condensation of atmospheric water vapour.

In section 6, an expansion of the particle model takes place. A substance particle is now called a 'molecule' and defined in terms of atoms. The initial concept of 'hold' is differentiated into 'bond' and 'intermolecular force'. A 'bond' is the strong hold between atoms making up a molecule and an 'intermolecular force' is a weaker hold between molecules. A substance, then, is defined by which atoms are bonded to which in its molecules. When all atoms in a molecule are the same the substance is an 'Element'. With two or more different atoms in a molecule, the substance is a compound. The idea of giant structures was not introduced as this was felt to be a step too far considering the age of the pupils. Instead, in cases where it was necessary, we focused on a small part of the representations of these structures working on their atoms and the corresponding bonds. There was also no reference to ions in any part of the teaching scheme.

In section 7 , the ideas of molecules and atoms are used to introduce the possibility of chemical change. The breaking and making of bonds between atoms results in substances changing into other substances. Generic simulations presented such changes at the atom level. In section 8, two chemical changes - the reaction between magnesium and oxygen (heating magnesium in the air) and the burning of a candle - were studied in depth, at the macroscopic and particulate levels. At the macroscopic level, a video was studied by the pupils for the magnesium reaction, whereas a live demonstration was used for the candle. At the particulate level for both 
Running head: Teaching primary pupils about chemical change

reactions, pupils worked on static diagrams (as extensions of the generic simulations presented in section 7).

Finally in section 9, some additional cases of chemical reactions were studied (using videos), to emphasise the change of substance at the macroscopic level. Importantly, the videos showed pure samples of all of the reactants and then all products after the reactions. Pupils rarely see all substances involved in a change (e.g., oxygen comes unseen from the air, solutions are already prepared when used).

The software

The software was derived from a pilot version of 'Stuff and Substance' (Author \#3 \& Other, 2003). For the needs of this research, the English text was translated into Greek and the content was adapted to the teaching scheme of Table 1. The user can follow the order of the materials (which matches Table 1) or choose to study a particular item from a main menu. The software contains:

- Texts, in which concepts and phenomena are discussed, analysed and explained.

- Simulations, which deal with the particulate level of analysis. Particle behaviour is simulated for all phenomena in the teaching scheme.

- Videos to show various phenomena at a macroscopic level

- Figures connected with points in the text, which could concern either particulate or macroscopic levels.

\section{Measurements and Instruments}

Thirty six pupils were interviewed individually a week before $\left(1^{\text {st }}\right.$ measurement) and a month after $\left(2^{\text {nd }}\right.$ measurement $)$ the intervention by the author 
Running head: Teaching primary pupils about chemical change

who had taught the lessons (author \#2). On the basis of their science assessments in the previous year, two boys and two girls were selected from high, intermediate and low bands of performance for each of the three classes.

The 'clinical type' interview with objects and events as stimuli for questioning (Posner \& Gertzog, 1982) was used for the collection of data. The same interview was used on all occasions. Table 2 presents an outline of the interview tasks and questioning. The interview has two main parts. In the first part (I), tasks target pupils' understanding of particle ideas in relation to the concept of substance. The tasks in part I are similar to those already used also in other pieces of our work (Authors \#1 \& \#3, 2005 ; Authors \#1, \#3 \& others, 2008). The second part (II) explores pupils' ideas on chemical change in terms of substances and whether they used ideas of atoms. The questioning was directed at the two main reactions covered in the intervention. Given the known challenges presented by chemical change, other examples were not used. It was enough to see if the pupils had made any headway on these specific cases. Postinterviews lasted up to an hour whereas pre-interviews were usually shorter due to pupils' limited ideas.

[Insert Table 2 about here]

\section{Data analysis}

After initial discussions, the interview data were qualitatively analysed and categorized by the first and the second authors, independently. Further discussion and negotiation took place involving the third author until final agreement was reached. 
Running head: Teaching primary pupils about chemical change

\section{Results and discussion}

Pupils' particle models

Part I of the interview (Table 2) explores two dimensions of pupils' understanding of particle ideas (Author \#3, 1998). The first relates to the relationship between the particles and the substance (tasks 1-3). Are the particles regarded as being the substance (a particulate view of matter) or are they something extra to continuous matter? The second concerns the explanation of the characteristic properties of a state. Do the particles themselves have the macroscopic properties or do the properties result from the collective behaviour of the particles, with their individual physical nature irrelevant (tasks 4-5)? The pupils' responses could be categorized into four particle models as follows:

Model X: Continuous substance - particle ideas have no meaning.

Model A: Particles in the continuous substance. In a particle diagram, the continuous substance is said to be between the particles.

Model B: Particles are the substance, but they have macroscopic character. In a particle diagram, the particles represent the substance - they are literally small bits of it.

Model C: $\quad$ Particles are the substance and properties of state are explained by their collective behaviour.

[Insert Table 3 about here]

Table 3 gives the category frequencies pre- and post-intervention. Looking at the pre- intervention figures in this Table, it is clear that the starting point for most pupils of the sample was model X. Few make any mention of particles and only two 
Running head: Teaching primary pupils about chemical change

pupils could be categorized in model B, at best. Post- intervention sees a considerable change in the distribution. The number exhibiting a particulate view (model B and above) is about one half of the sample (17). Similar results have occurred in other studies involving sections 1-4 of the teaching scheme (Authors \#1 \& \#3, 2005; Authors \#1, \#3 \& others, 2008). On a first exposure, this could be considered more or less an expected result. However, the distribution between models B and C could vary according to the teaching methods, means etc. In the study of Author \#1, \#3 \& others (2008), where software was used, the proportion of pupils categorized as model C was higher. The software may account for the good number in model C in this study (11). These pupils seem to understand both particulate and collective dimensions of the basic particle theory. Another possibility is that ideas of atoms helped pupils to move to model $\mathrm{C}-$ atoms do not fit with model B.

\section{Explanations of chemical phenomena}

The questioning in part II on the reaction between magnesium and oxygen and a burning a candle elicited a wide range of responses. From not recognizing any changes in substances to the scientific account these could be put into five categories. Table 4 presents these categories and their frequencies for pre- and post- intervention pupil responses.

[Insert Table 4 about here]

Looking at Table 4, there are similarities but also differences between pupils' responses to the two phenomena. In keeping with the literature, the candle is more 
Running head: Teaching primary pupils about chemical change

difficult than the magnesium oxide. We will consider the pre-intervention responses for each phenomenon first and then the post-intervention responses.

Pre-intervention, for the reaction between magnesium and oxygen, all but one of the pupils' responses are in categories 1 to 3 . The accumulation of 16 pupils in category 1 is probably due to their lack of familiarity with the phenomenon. These pupils focused on the emitted light and not the change in material. In accord with stage one of Stavridou and Solomonidou (1998), it is an event where something happens. Pupils in the second and third categories did pick up on the material change. Those in category 2 focused on the external look of the material - the change in form from grey pieces to a white powder: i.e. what could be seen which did not include oxygen. There was no indication that the grey pieces and white powder were regarded as different substances. Pupils in the third category saw the event as a kind of 'unmixing'. The magnesium oxide was inside the magnesium and came out - two of these pupils tried to explain that this happens because of the heating. In this sense the white powder already existed - there was not a change of substance as such.

The pupil in category $4(\mathrm{P} 2)$ is exceptional and was noted by his class teacher as being especially interested in science. Although he did not understand what exactly a molecule means, he used the term and there was no reference to oxygen:

P2 aaa!!!... it is about burning

I $\quad$ what do you mean?

P2 the magnesium is burning?

I how this happens? Can you explain this to me?

P2 the molecules of magnesium lose their connections between each other due to the heating, change their arrangement into a new way of arrangement and thus a new substance is formed. 
Running head: Teaching primary pupils about chemical change

In contrast to the magnesium and oxygen reaction, a burning candle is familiar to pupils. Most of the sample focused on the wax melting as if this was all that was going on (category 2). Such responses are commonly reported in the literature (e.g., Abraham, Gizybowski, Renner \& Marek, 1992, Abraham \& Williamson, 1994; Author \#3, 2002; Çalik \& Ayas, 2005). Only one of these pupils (P23) attempted to explain the change: 'The molecules of wax are heating and start to move more. As a result, the molecules go apart from each other and so... the wax becomes a liquid'. One of the three pupils in category 1 just said that he did not know what happens to the wax. Another said, initially, that 'the wax is burning' but could go no further. The third pupil said that the missing part of wax after burning just disappears. Of the two pupils in category 3 , one talked about the formation of smoke as something new - the missing part of the wax after burning 'is due to the smoke that is formed'. The other talked about the formation of a new liquid (different to wax) that was inside the wax and came out due to the heat. For all pupils, the soot and condensation forming on a glass held above a flame were a mystery.

Post- intervention, the distribution among the categories of Table 4 changes towards higher categories for both phenomena, though more so for the reaction between magnesium and oxygen. Most pupils still view the candle as a physical phenomenon.

For the reaction between magnesium and oxygen, three pupils recognized the change as a change which gave a new substance and were able to provide an explanation in terms of atoms (category 5). Pupil P3 explained as follows:

I what do you mean 'magnesium is burning'?

P3 magnesium compounds with oxygen

I $\quad$ and how this happens? Can you explain this to me? 
Running head: Teaching primary pupils about chemical change

P3 these bonds break (he sloppily drew oxygen-oxygen bonds) ... they change their place, they form new bonds with magnesium atoms (he drew bonds oxygen-magnesium)... and this is a new substance.

I and why we have to heat magnesium for this?

P3 ...the energy of atoms changes due to heating ... and the bonds between the atoms break. The atoms change their position, new bonds are formed between magnesium and oxygen and a new substance is formed.

However, the majority of pupils, who tried to explain the phenomenon as a chemical one, could not give such a satisfying explanation (category 4). In this category, pupils could also recognize the production of a new substance but their explanations were incomplete and commonly included a number of misunderstandings or lack of distinction between concepts (e.g. atom/ molecule/ particle). Typically, the incompleteness concerned specific reference to 'bonds' and the rearrangement of atoms. For example, pupil P12:

P12 magnesium compounds with oxygen, a flash come out and something new is formed

I and how this happens?

P12 magnesium comes together with oxygen

I and why we have to heat magnesium for this?

P12 because heating increases the energy of particles and magnesium particles move faster and it turns into gaseous state and so ... particles of magnesium and oxygen can come together ... (no reference to bonds) 
Running head: Teaching primary pupils about chemical change

The quality of the responses for categories 1,2 and 3 were much the same as before.

Only a few pupils are in categories 4 and 5 for the burning candle, postintervention (Table 4). Again, the large majority were in category 2 - even some of those pupils in the highest categories for the magnesium reaction. Pupil 29, is an example of one of the two category 5 responses:

P29 ... because of the heat, particles move more ... and wax become liquid and then gas and then ... it compounds with oxygen

I $\quad$ what do you mean by 'it compounds with oxygen'?

P29 The bonds between atoms are broken in both wax and oxygen ... and atoms of hydrogen and carbon make new bonds with atoms of oxygen. ...Thus, water is formed and the other substance with carbon and oxygen (he didn't referred to carbon dioxide as such)

I And what is this? (Droplets on the glass)

P29 Water ... Atoms of hydrogen from wax compound with oxygen from air.

I $\quad$ and what is this soot?

P29 This is carbon which didn't burn ... it couldn't compound with oxygen.

Those in category 4 did not refer to atoms and bonds and their incomplete explanations were not entirely correct. Misunderstandings over the transfer between the macro and particulate levels were also evident. For example, Pupil 19: 'These are (droplets) due to the particles of wax, the white ones, which are compounded with oxygen and formed water particles.... This (soot) is ... due to the particles of wax, the 
Running head: Teaching primary pupils about chemical change

black ones, which could not compound with oxygen ...' In this particular case, the reference to black and white particles was due to the use of these colours in the representation of carbon and hydrogen atoms during the intervention, as Figure 1 shows. The choice of black for carbon might not be helpful.

[Insert Figure 1 about here]

Most pupils did not view the candle as a chemical phenomenon. As noted, the large majority (25 pupils) focused on the change of state, only. However, about half of these pupils did provide an explanation using basic particle ideas, and some also included the change to the gas state ( 8 out of the 12). Pupil P28 for instance explained: 'Wax is melting ... and a part of it evaporates. The energy of wax particles is increasing due to heating ... particles of wax move more freely and they can pass from the solid to the liquid state ... and then to the gas state. ...' Pupil P27 gave a similar response, adding: '... The part of wax which cannot evaporate is running as liquid wax from the side of the candle'. Although such explanations stop short of the chemical change, wax changing from solid through liquid to the gas state is a prerequisite. It is the first step on the way to understand the burning candle (the next step is the mixing of wax gas with oxygen and the final is the chemical one).

The two pupils in category 3 described the change in terms of mixing and unmixing of already existing substances. For instance, pupil P13 described the phenomenon as follows: '... some wax particles lost their ability to hold on together, the wax became a gas and its particles mixed with the oxygen of the air', whereas for the formation of water and soot he explained: 'this is water...it was in the air as gas and now is in the liquid state... . This (soot) came from the carbon, which was in the 
Running head: Teaching primary pupils about chemical change

wax ...'. Again, this category also includes useful ideas on the way to understand the phenomenon, but it is still a distance from the idea of the chemical change.

Looking across the two events, post-intervention, all of the pupils in category 4 (13 magnesium 5 candle) referred to an interaction with oxygen during their explanations. This may be an important sign of progress. The findings of other studies (e.g. Watson, 1995; Author \#3, 2002; Liu \& Lesniak, 2006) show it is not very common for the pupils to mention invisible substances in such phenomena, especially at younger ages below grade 8. However, as noted by Boujaoude (1991) and Author \#3 (2002) the key issue is what is understood by oxygen. Author \#3 (2002) suggests that pupils' difficulties can arise because they do not think of 'gases' as substances. Instead of solid, liquid and gas being three states which are a possibility for a substance, they think 'solids, liquids and gases' are three separate types of matter, where 'gases' are very mysterious. In which case, they cannot see how a gas could interact with a solid as in the reaction between magnesium and oxygen. Perhaps there is an indication that the intervention, with its emphasis on substances and particles, had moved these pupils towards accepting that a gas such as oxygen is a substance.

One pupil was in category five for both events - P2, the exceptional pupil noted earlier.

Relation between pupils' particle models and pupils' explanations, post-intervention.

For the post-intervention interview, Table 5 cross-tabulates the pupils' particle models (from part I) and the pupils' explanations for each of the two chemical changes (from part II). Three regions in Table 5 are distinguished by shading: category 5, category 4 and the lower categories (1-3). 
Running head: Teaching primary pupils about chemical change

[Insert Table 5 about here]

In the first region we see that the four pupils who used ideas of atoms and bonds (category 5 for one or both events) also held model C. This is not too surprising. It follows that a sound understanding of atoms requires a sound understanding of a basic particle model. Author \#3 (2002) found similarly: those pupils who explained the reaction between copper and oxygen in terms of atoms were also at model C. However, model $\mathrm{C}$ is not automatically associated with the use of atoms to explain chemical change. Three only used the ideas for one of the events and other model C pupils are in lower categories. Seven are in category 4 for magnesium and four for the candle. Overall, model $\mathrm{C}$ pupils make up a high proportion of those in category 4 , and their understanding of the particle model could be helping them to begin thinking about chemical change. Some pupils with model A are also in category 4. Given the nature of the model it may well not be helping them in any way. However, in other studies (Author \#3, 1998; Author \#1 \& \#3, 2005) there have been examples where pupils have used the particles to somehow represent the substance even if they didn't understand the particles to be the substance. For magnesium, although pupil P12 could not deal very well with the concept of 'bond', he could use particle ideas to explain how a substance can change its state and how particles of two different substances could come together in order to have something new. We would not expect to find a model A pupil in category 5. No model X pupils are in category 4.

Below category 4 , there is no clear picture. Those category 2 pupils who talked about the wax changing through to the gas state (rather than just liquid) were those with models $\mathrm{C}$ and $\mathrm{B}$. The model $\mathrm{C}$ pupil in category 1 for magnesium is an anomaly. This pupil's responses for both magnesium and the candle (category 2) did 
Running head: Teaching primary pupils about chemical change

not change at all: knowledge of particle ideas had no impact on understanding the chemical phenomena.

\section{Conclusions}

Foremost, the results of this study confirm that chemical change is a very difficult idea for pupils to grasp. Furthermore, the pupils' responses to the two cases indicate that each chemical phenomenon makes its own characteristic demands. A burning candle seems to be significantly more difficult than the reaction between magnesium and oxygen. Given the range of chemical phenomena, developing an understanding of chemical change is likely to be a graduated process, with understanding emerging in some contexts before others. A better understanding of which contexts are more accessible would be useful to know. At present, chemical change is often treated as if it were a single phenomenon.

A prerequisite for understanding chemical change must be an understanding of physical changes. Here, as already argued, we believe the approach should be through the concept of a substance and its states, rather than generic 'solids, liquids and gases'. On this, over the course of the relatively short intervention, progress was encouraging and suggests particle ideas are not beyond the reach of young pupils. A sustained program over a longer time span could result in most pupils engaging profitably with the ideas. Research involving longer interventions is needed. Nevertheless, even with a focus on the concept of a substance for physical changes, the idea of substances changing into other substances is not a simple next step (even with the use of software). Nevertheless, although there was no control group, in the pupils' responses there were indications that particle ideas were contributing. Firstly, particle ideas had helped those pupils in category 4 to think of oxygen as something. 
Running head: Teaching primary pupils about chemical change

At least, they were beginning to think of the changes as interactions, which is moving towards Andersson's highest category of chemical interaction (Andersson, 1990). Here, even model A might have been of some use. However, an interaction could be interpreted in many ways - for example, as a mixing rather than something which leads to the creation of new substances at the expense of the original substances. Only those who used ideas of atoms had accepted chemical change, in a particular context, for what it is. Of course, strictly speaking this is simply a coincidence and a direction of causality cannot be proven. However, none of the other pupils seemed happy with the notion of a chemical change on the basis of macroscopic observations. Paradoxically, the obvious and often spectacular features of those chemical changes normally used to introduce the phenomenon may be part of the problem. Flashes of light, melting wax and bubbles (when gases are not understood to be substances) are distracting. It is difficult for pupils to see beyond these phenomenological features, Stavridou and Solomonidou's (1998) first stage. Perhaps, and this is pure speculation, chemical change should be introduced with less spectacular examples and ones that do not involve the gas state, and powders. For example, reactions normally reserved for later in the curriculum such as between ethanol and ethanoic acid to produced ethylethanoate and water, or the production of soap and glycerol from olive oil and sodium hydroxide. Without the distractions, pupils might be able to better focus on the change of substance.

Should we teach young pupils about chemical change? On the evidence so far, we are skeptical about introducing the phenomenon to pupils up to ages $11 / 12$. A limited number of pupils in this study made impressive progress (with one seeming to have a head start). However, most were in the process of coming to terms with the first level particle ideas, and atoms and chemical change was too big a next step. 
Running head: Teaching primary pupils about chemical change

From a questionnaire-based study on Greek students starting secondary school, Georgousi, Kampourakis \& Tsaparlis (2001) recommend that particulate ideas are only appropriate for the most able in the upper primary school. At the level of atoms we agree that things are not so simple for the average pupil at those ages. Given also pupils' difficulties with accepting chemical change on a macroscopic basis we would suggest further research work on optimizing the ways and methods to introduce chemical change in the primary curriculum. In this respect, we acknowledge that the short timescale of the study did not allow sufficient preparation for lessons 6-9. Taking also into account that a first level substance-based particle model to explain physical changes, appears to be appropriate for pupils at primary level, from age 9 onwards (Authors \#3 \& \#1, 2009; Authors \#1 \& \#3, 2005), time to consolidate the ideas in a wide range of contexts would be well spent here. After establishing the concept of a substance in this way, upper primary pupils might enjoy greater success with the idea of chemical change. Ideas of atoms could be used to predict the possibility of chemical change, which might be best illustrated first with nonspectacular examples.

\section{References}

Ahtee, M., \& Varjola, I. (1998). Students Understanding of Chemical Reaction. International Journal of Science Education, 20, 305-316.

Abraham, M. R., Gizybowski, E. B., Renner, J. W., \& Marek, E. A. (1992). Understandings and misunderstandings of eighth graders of five chemistry concepts found in textbooks. Journal of research in science teaching, 29(2), 105120. 
Running head: Teaching primary pupils about chemical change

Abraham, M. R., Williamson, V. M., \& Westbrook, S. L. (1994). A cross-age study of the understanding of five chemistry concepts. Journal of research in science teaching, 31(2), 147-165.

Andersson, B. (1990). Pupils' conceptions of matter and its transformations (age 1216). Studies in science education, $18,53-85$.

Ardac, D., \& Akaygun, S. (2005). Using static and dynamic visuals to represent chemical change at molecular level. International Journal of Science Education, 27 (11), 1269-1298.

Author \#3 (1996). Education in Chemistry.

Author \#3 (1998). International Journal of Science Education.

Author \#3 (2000). International Journal of Science Education.

Author \#3 (2002). International Journal of Science Education.

Author \#3 \& Other (2003) Stuff and Substances, pilot version 1.0

Authors \#1 \& \#3 (2005). International Journal of Science Education.

Authors \#1, \#3 \& others (2008). Research in of Science and Technological Education.

Authors \#3 \& \#1 (2009). Journal of Research in Science Teaching (in press).

Boo, H-K., \& Watson, J. R. (2001). Progression in high school students' (Aged 1618) conceptualizations about chemical reactions in solution. Science education, $85,568-585$.

Boujaoude, S. B. (1991). A study of the nature of students' understanding about the concept of burning. Journal of research in science teaching, 28(8), 689-704.

Briggs, H. \& Holding, B. (1986). Aspects of secondary students' understanding of elementary ideas in chemistry. Centre for Studies in Science and Mathematics Education, University of Leeds. 
Running head: Teaching primary pupils about chemical change

Brosnan, T., \& Reynolds, Y. (2001). Student's explanations of chemical phenomena: macro and micro differences. Research in science and technological education, 19(1), 69-78.

Calik, M., \& Ayas, A. (2005). A comparison of level of understanding of eighth-grade students and science student teachers related to selected chemistry concepts. Journal of research in science teaching, 42(6), 638-667.

Cokelez, A., Dumon, A., \& Taber, K.S. (2008). Upper secondary French students, chemical transformations and the 'Register of models': A cross-sectional study. International journal of science education, 30 (6), 807-836.

Georgousi, K., Kampourakis, C., \& Tsaparlis, G. (2001). Physical-science knowledge and patterns of achievement at the primary-secondary interface, part 2: able and top-achieving students. Chemistry Education: Research and Practice in Europe, 2(3), 253-263.

Greek Pedagogical Institute (1999). National Program of Study for Primary and Secondary Education: Science, Athens - Greece, Greek Pedagogical Institute Publications.

Driver, R. (1985). Beyond appearances: the conservation of matter under physical and chemical transformations. In R. Driver, E. Guesne, \& A. Tiberghien (Eds.), Children's ideas in science (pp 145-169). Milton Keynes, UK: Open University Press

Kozma, R., \& Russell, J. (1997). Multimedia and understanding: expert and novice responses to different representations of chemical phenomena. Journal of Research in Science Teaching, 34(9), 949-968.

Liu, X., \& Lesniak, K. (2006). Progression in children's understanding of the matter 
Running head: Teaching primary pupils about chemical change

concept from elementary to high school. Journal of research in science teaching, 43(3), 320-347.

Meheut, M., Saltiel, E., \& Tiberghien, A. (1985). Pupils' (11-12 year olds) conceptions of combustion. European Journal of Science Education, 7(1), 83-93.

Posner, C. J., \& Gertzog, W. A. (1982). The clinical interview and the measurement of conceptual change. Science Education, 66, 195-209.

Shrank, P., \& Kozma, R. (2002). Learning chemistry through the use of a representation-based knowledge building environment. Journal of Computers in Mathematics \& Science Teaching, 21 (3), 253-279.

Solsona, N. J., Izquierdo, M., \& De Jong, O. (2003). Exploring the development of students' conceptual profiles of chemical change. International journal of science education, 25(1), 3-12.

Stains, M. \& Talanquer, V. (2007). Classification of Chemical Substances using Particulate Representations of Matter: An analysis of student thinking. International Journal of Science Education, 29(5), 643-661.

Stavridou, H., \& Solomonidou, C. (1989). Physical phenomena - chemical phenomena: Do pupils make the distinction? International Journal of Science Education, 11(1), 83-92.

Stavridou, H., \& Solomonidou, C. (1998). Conceptual reorganization and the construction of chemical reaction concept during secondary education. International journal of science education, 20(2), 205-221.

Stieff, M., \& Wilensky, U. (2003). Connected chemistry - Incorporating interactive simulations into the chemistry classroom. Journal of Science Education \& Technology, 12(3), $285-302$. 
Running head: Teaching primary pupils about chemical change

Taber, K. S. (2001). Building the structural concepts of chemistry: Some considerations from educational research. Chemistry Education: Research and Practice in Europe, 2(2), 123-158.

Talanquer, V. (2006). Commonsense chemistry : A model for understanding students' alternative conceptions. Journal of Chemical Education, 83 (5), 811816.

Talanquer, V. (2007). Students' predictions about the sensory properties of chemical compounds: additive versus emergent frameworks. Science Education, 92, 96114.

Tao, P.-K., \& Gunstone, R.F. (1999). The process of conceptual change in force and motion during computer-supported physics instruction. Journal of Research in Science Teaching, 36(7), 859-882.

Watson, R. (1995). The effect of practical work on students' understanding of combustion. Journal of Research in Science Teaching, 32(5), 487-502. 
Running head: Teaching primary pupils about chemical change

Table 1: Outline of content of the teaching scheme.

\section{Properties and the material/object distinction}

Some properties depend on the material only.

Some properties depend on the material, the amount (dimensions of an object) and the shape/structure of an object.

\section{Definition of a substance.}

Melting behaviour can be used to distinguish between a pure sample of a substance and a mixture of substances.

\section{A simple particle model}

Particle ideas can explain melting.

A sample of a substance was presented as a collection of particles with empty space between. Key points were:

- The particles have an ability to "hold on" to each other.

- They are always moving in some way (energy of movement).

- The particles of a particular substance remain the same in a change of state.

\section{A sample of a substance could be in one of three states.}

A sample of a substance can be in the gas state.

Explanations for the phenomena of melting and boiling.

Why different substances can be in different states at room temperature.

\section{Mixing and unmixing.}

Air as a mixture of substances in the gas state.

Condensation of atmospheric water vapour.

\section{The structure of the substances}

Distinction of particles into atoms and molecules.

What the atom is.

What the molecule is.

Distinction of "hold" into bonds and intermolecular forces.

What the bond is.

Elements and compounds.

\section{The chemical change}

Some changes lead to the formation of new substances.

What a chemical change is.

Chemical reactions.

\section{Explaining some chemical reactions (macro-, micro- levels)}

Reaction between magnesium and oxygen

Burning a candle

\section{Gaining experience in some other chemical reactions (mainly in macro- level)}

Reaction between calcium and water

Reaction between potassium iodide and lead nitrate

Reaction between ammonia and hydrogen chloride 
Running head: Teaching primary pupils about chemical change

Table 2: An outline of the interview tasks.

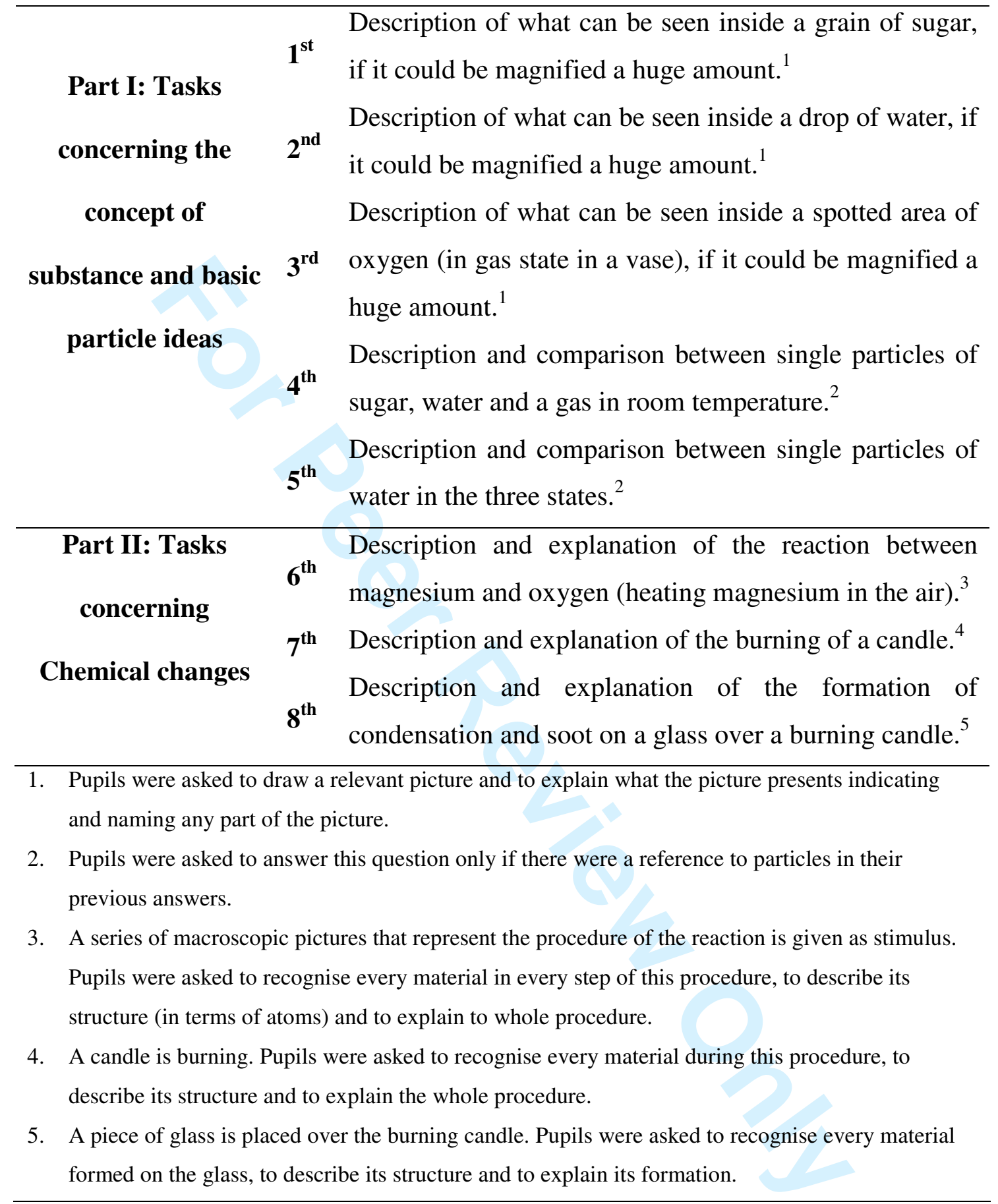


Running head: Teaching primary pupils about chemical change

Table 3: Frequencies of pupils' particle models.

\begin{tabular}{ccccc}
\hline Model & X & A & B & C \\
\hline Pre & 29 & 5 & 2 & - \\
Post & 9 & 10 & 6 & 11 \\
\hline
\end{tabular}


Running head: Teaching primary pupils about chemical change

Table 4: Frequencies of pupils' explanation levels concerning chemical phenomena

\begin{tabular}{|c|c|c|c|c|c|}
\hline & \multirow[b]{2}{*}{ Pupils' categories } & \multicolumn{2}{|c|}{$\begin{array}{c}\text { Magnesium \& } \\
\text { oxygen (Pupils) }\end{array}$} & \multicolumn{2}{|c|}{$\begin{array}{l}\text { Burning candle } \\
\text { (Pupils) }\end{array}$} \\
\hline & & $\begin{array}{c}1^{\text {st }} \\
\text { Measur. }\end{array}$ & $\begin{array}{c}2^{\text {nd }} \\
\text { Measur. }\end{array}$ & $\begin{array}{c}1^{\text {st }} \\
\text { Measur. }\end{array}$ & $\begin{array}{c}2^{\text {nd }} \\
\text { Measur. }\end{array}$ \\
\hline 5 & $\begin{array}{l}\text { Pupil understands chemical change as } \\
\text { an interaction between substances } \\
\text { which produces new substances and } \\
\text { can explain the change using ideas of } \\
\text { atoms. }\end{array}$ & - & 3 & - & 2 \\
\hline 4 & $\begin{array}{l}\text { Pupil appreciates that a chemical } \\
\text { change involves an interaction between } \\
\text { substances which leads to new } \\
\text { substances but, at best, can only give } \\
\text { an incomplete explanation using } \\
\text { particle ideas }\end{array}$ & 1 & 13 & - & 5 \\
\hline 3 & $\begin{array}{l}\text { Pupil recognises a change in terms of } \\
\text { mixing or unmixing of the preexisting } \\
\text { substances.(Some of them tried to } \\
\text { explain the change) }\end{array}$ & $13(2)$ & $3(-)$ & $2(-)$ & $3(2)$ \\
\hline 2 & $\begin{array}{l}\text { Pupil focuses on changes of state or } \\
\text { form*. (Some of them tried to explain } \\
\text { the change). }\end{array}$ & $6(-)$ & $5(1)$ & $31(1)$ & $25(12)$ \\
\hline 1 & $\begin{array}{l}\text { Pupil does not recognise any changes } \\
\text { in any substances }\end{array}$ & 16 & 12 & 3 & 1 \\
\hline
\end{tabular}


Running head: Teaching primary pupils about chemical change

Table 5: The relationship between pupils' particle models and pupils' explanations of the reaction between magnesium and oxygen, and the burning candle.

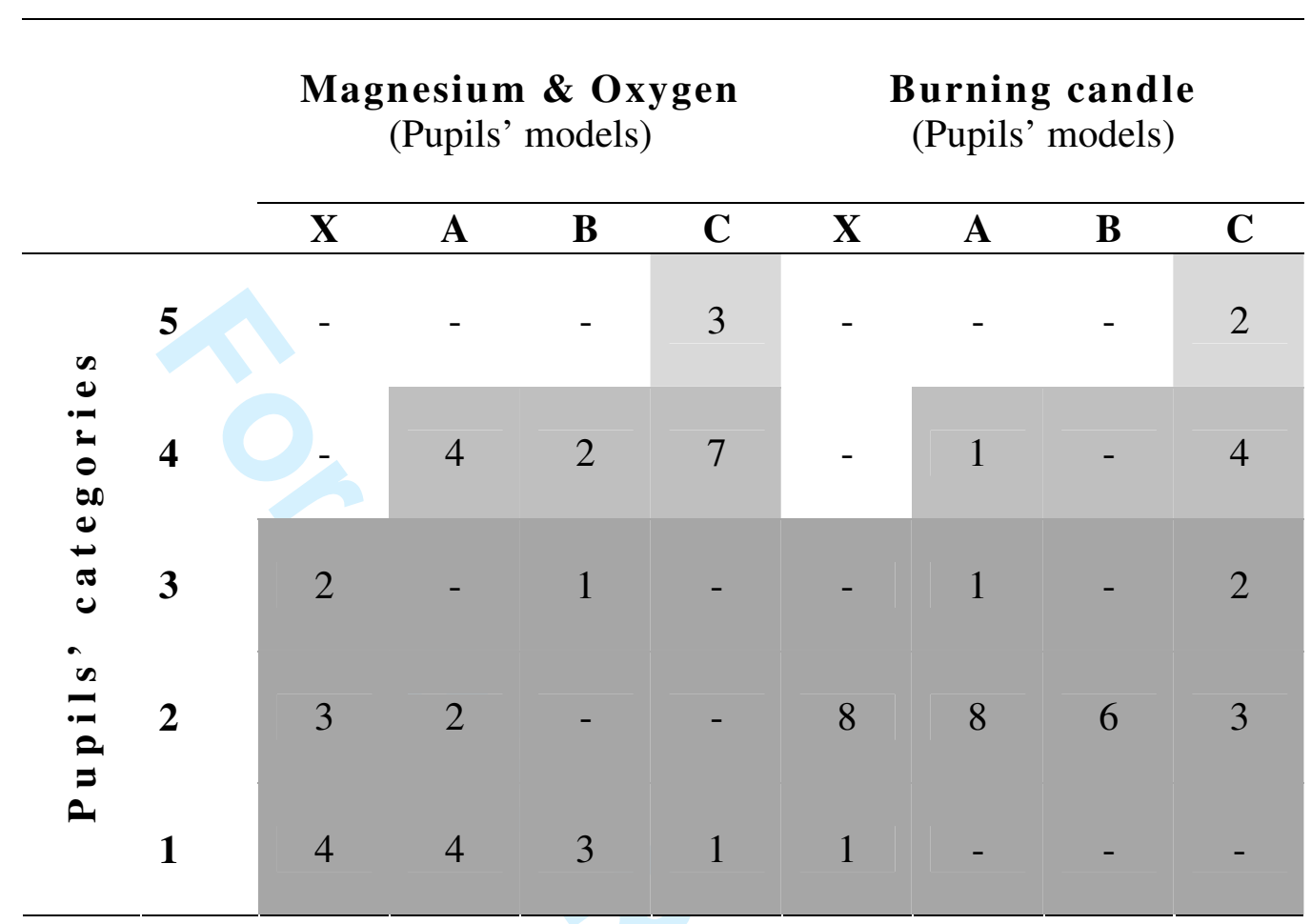




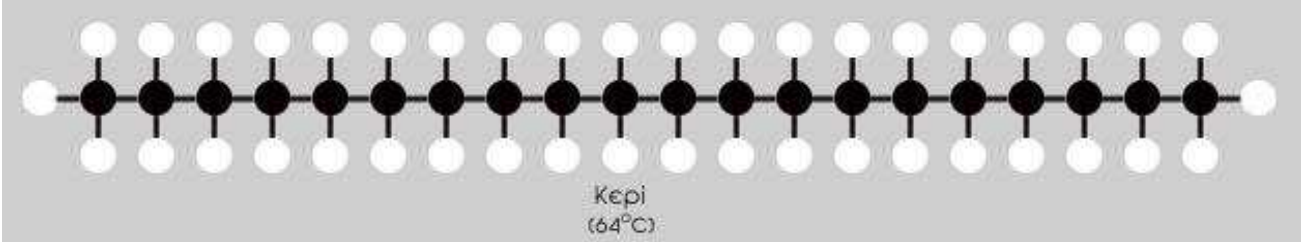

Figure 1: The molecule of wax, as it was presented to the pupils using the software. $166 \times 31 \mathrm{~mm}(96 \times 96 \mathrm{DPI})$

URL: http://mc.manuscriptcentral.com/tsed Email: editor_ijse@hotmail.co.uk 